\title{
An overview on the seismic microzonation and site effect studies in Central Asia
}

\author{
Marco Pilz ${ }^{1, \star}$, Tanatkan Abakanov ${ }^{2}$, Kanatbek Abdrakhmatov ${ }^{3}$, Dino Bindi ${ }^{1}$, \\ Tobias Boxberger ${ }^{1}$, Bolot Moldobekov ${ }^{4}$, Sagynbek Orunbaev ${ }^{4}$, Natalya Silacheva ${ }^{2}$, \\ Shahid Ullah ${ }^{1}$, Sheyshenaly Usupaev ${ }^{4}$, Pulat Yasunov $^{5}$, Stefano Parolai ${ }^{1}$ \\ ${ }^{1}$ Helmholtz Center Potsdam - German Research Center for Geosciences, Potsdam, Germany \\ ${ }^{2}$ Institute of Seismology, Academy of Sciences of the Republic of Kazakhstan, Almaty, Kazakhstan \\ ${ }^{3}$ Institute of Seismology, Academy of Sciences of the Kyrgyz Republic, Bishkek, Kyrgyzstan \\ ${ }^{4}$ Central Asian Institute for Applied Geosciences, Bishkek, Kyrgyzstan \\ ${ }^{5}$ Institute of Geology, Earthquake Engineering and Seismology, Academy of Sciences of the Republic of Tajikistan, \\ Dushanbe, Tajikistan
}

\author{
Article history \\ Received September 17, 2014; accepted November 24, 2014. \\ Subject classification: \\ Site effects, Seismic noise, Earthquake, Microzonation.
}

\begin{abstract}
During the past centuries, many cities in Central Asia have suffered significant damages caused by earthquakes. A crucial step towards preparedness for future events, the definition of the optimal engineering designs for civil structures and the mitigation of earthquake risks involves the accomplishment of site response studies. To accurately identify local variations of the site response at different locations within the cities, earthquakes recorded by seismic networks as well as measurements of the seismic noise can be used for estimating the resonance frequencies and for evaluating the expected level of ground motion at each site. Additionally, the measurements can help identifying site specific features like more-dimensional resonances and directional effects. This information can be complemented with array measurements of ambient seismic noise in order to estimate local shear-wave velocity profiles, an essential parameter for evaluating the dynamic properties of soil, and to characterize the corresponding sediment layers at each site. The present study gives an overview on the progressive development of the seismic zonation studies in the frame of EMCA carried out in several cities in Central Asia.
\end{abstract}

\section{Introduction}

As evidenced by its historical seismicity, Central Asia is a region prone to large earthquakes, mainly due to the Asia-India continental collision where the northward-moving Indian plate indents the Eurasian plate [see e.g., Molnar and Tapponnier 1975]. Both seismic data, including the spatial distribution of earthquakes, associated fault plane solutions, and surface deformation, as well as geologic evidence of recent tectonic ac- tivity, imply deformation in a broad zone extending as much as $3000 \mathrm{~km}$ northwest of the Himalayas.

Given the high seismic activity in the area, early activities were carried out for quantifying the level of seismic hazard. An early seismic zoning map of the former USSR and adjacent territories compiled by Gorshkov [1937] was one of the first of its kind in the world. Notably, it was the first prognostic map of seismic hazard because it did not only identify territories with known historical earthquakes as endangered but it did specify five zones of "geological similarity" (respective for intensities V to IX) extending from areas of former seismic events. Successive seismic zoning maps of the USSR were released in 1957, 1968 and 1978. These maps were also incorporated in national engineering codes. The general seismic zoning (GSZ) map of 1978 [Bune and Gorshkov 1980] included both boundaries of shaking intensities with zones for intensities from VI to IX on the MSK64 scale [Medvedev et al. 1964] as well as zones of most probable locations of severe earthquakes, differentiated by the maximum expected magnitude. The GSZ maps were accompanied by seismic zoning maps at different spatial scale like the detailed seismic zoning (DSZ) and the seismic micro-zoning (SMZ) maps. Such maps were characterized not only by a different spatial scale, but also by taking into account local seismo-tectonic, seismic, ground and other natural conditions along with regional ones. In partic- 
ular, in the SMZ constructed for most of the main towns in Central Asia, the influence of local site amplifications was also accounted for introducing intensity increments related to local geological conditions. By the end of 1990, SMZ maps projecting intensity as a function of soil and topography in limited areas had been compiled for ten large cities in the USSR [McGuire 2004] including all five capitals of the Central Asian Soviet republics.

Following the collapse of the Soviet Union in 1991, seismic hazard in terms of intensities was re-assessed for many capitals of the now independent countries in Central Asia. However, the studies, mainly following a probabilistic approach, were carried out on a national level and, therefore, not in a homogeneous way (for a review see Nurmagambetov et al. [1999]). As an example, DSZ maps in terms of both intensity and peak ground acceleration were constructed for the suburbs of Almaty (formerly known as Alma-Ata; Kyurskeyev et al. [1993]) and the probabilistic values of seismic hazard in Almaty were assessed in terms of peak accelerations and intensity [Mikhailova 1996]. For Tashkent (Uzbekistan) and Bishkek (Kyrgyzstan), new probabilistic assessments have been computed by Erdik et al. [2005]

However, the need for updating and harmonizing existing information in the different countries is obvious since, over the last century alone, large parts of Central Asia have been heavily damaged by earthquakes and many cities had been partially or even totally destroyed. As an example, Tashkent, Uzbekistan's capital, was leveled by a $\mathrm{M}=5.2$ earthquake in 1966 , whose epicenter was right below the town, with over 300,000 people reported homeless [Ulomov and Mavashev 1971]. Ashgabat, Turkmenistan's capital, was substantially destroyed in 1948 by a $M=7.3$ earthquake along with 110,000 to 176,000 deaths reported, equivalent to more than $10 \%$ of the Turkmen SSR's population at that time [Penuel and Statler 2010]. Almaty, Kazakhstan's largest city and its former capital, was severely damaged by earthquakes repeatedly between 1887 and 1911. Dushanbe, the capital of Tajikistan, experienced an $\mathrm{M}=7.4$ earthquake in 1907. Altogether, since 1900, all Central Asian countries have suffered approximately 280,000 deaths directly related to earthquakes [GeoHazards International 1996]. In addition, within the last 60 years, Central Asia has seen a multiplication of its population from 18 million in 1951 to more than 53 million in 2010 [Andreev et al. 1993, Lutz 2010], accompanied by an extreme increase of the urbanization rate from around $25 \%$ in the 1950 s to more than $50 \%$ nowadays. Therefore, the high level of seismic activity in the entire territory poses a continuous threat to safety of human life and might severely affect the social and economical de- velopment of the country. An increase of knowledge along with awareness of local authorities and decision makers of the possible consequence of a large earthquake is mandatory to mitigate the effects of an earthquake. To accomplish this task it is indispensable to assess the level of seismic hazard and risk for the cities. However, high-level hazard assessment should be performed only after having considered the effect of shallow geological material in modifying earthquake ground motion as well as topographic effects due to focusing and/or scattering of seismic waves. The preparation of detailed maps of local site effects and seismic microzonation of the territories of major cities and industrial facilities is highly justified since these maps are of high economic and social importance because they can generally be used for a rational placement and distribution of industrial and urban buildings. Scientifically based quantitative data about the nature and the effects of strong earthquake ground shakings are therefore unavoidable to take anti-seismic measures, contributing to a seismic risk reduction and to public safety. To this regard, the Earthquake Model Central Asia (EMCA), a regional program of the Global Earthquake Model (GEM), aims at a harmonized cross-border assessment of seismic hazard for strategically important cities in Central Asia.

In this article, we give an overview of site response studies conducted recently or being underway in different Central Asian cities (the cities are indicated in Figure 1). These studies incorporate not only seismic data, but also further data and results from additional geophysical studies. The final result of the works undertaken is the mapping of site specific features of ground motion for major cities in due consideration of new methodologies for the evaluation of amplification of ground motion.

\section{Site effect studies}

Extended mountain valleys with wide plains of fluvial deposits as well as lakeshores are particularly prone to seismic site amplification and nonlinear effects. In former times, such seismically unfavourable sites would have been attractive for spacious settlements and industries, and many cities worldwide have grown extensively over such plains and are still expanding. Given this spread of urban populations into areas of unfavourable soils, future earthquakes might cause extensive human and economic damage because geometrical and mechanical features of soft deposits have a great influence on seismic wave propagation and amplification.

Earthquake ground motion may be amplified close to the free surface by purely geometrical effects 


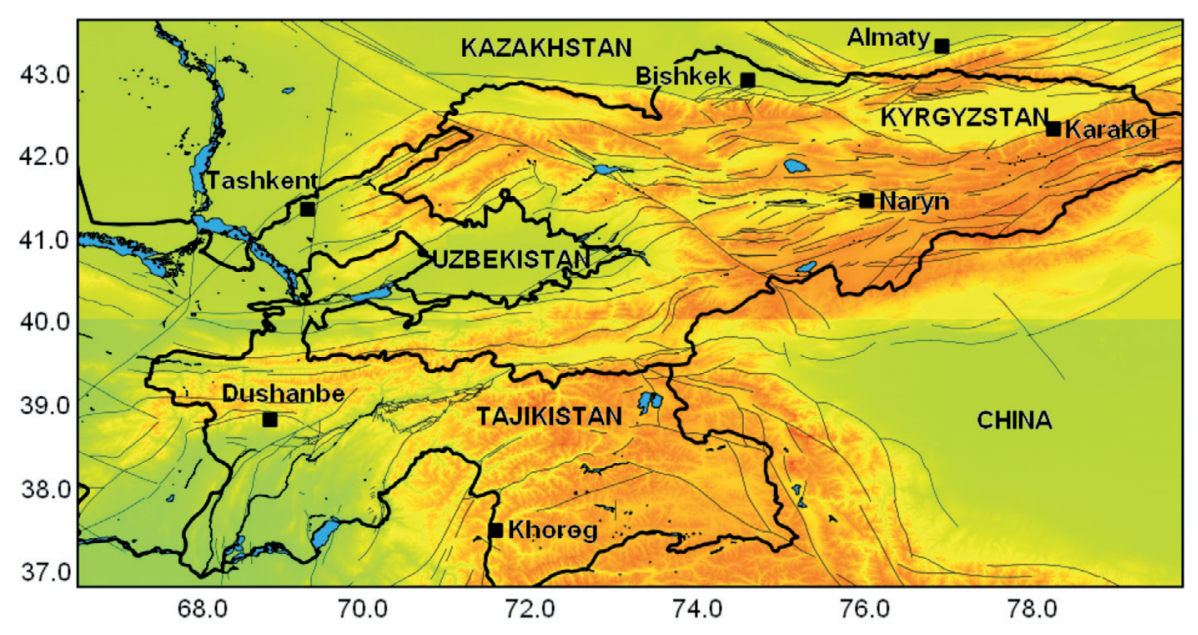

Figure 1. Map of Central Asia indicating all cities in which site effects studies have been carried out. The main active faults (thin black lines; Trifonov et al. [2002]) are indicated.

(i.e., topographic effects). In this case, the irregular surface geometry will focus incoming energy at some places, increasing the amplitude of ground motion, and defocus it at other locations, decreasing observed motion. On the other hand, the level of ground motion can be modified due to stratigraphic effects caused by the velocity contrast between the sedimentary soil layers and the bedrock. In this case, seismic energy approaching the Earth's surface will travel through material with decreasing stiffness. Conservation of energy (or rather conservation of energy flux) requires that the waves remove energy from the interface between two materials at the same rate at which it arrives. If the impedance of the upper layer is smaller, the only way to do this is to increase the amplitude of the transmitted wave. Hence, the seismic response might be influenced both by the local geology, which often leaves significant imprint on seismic motion by amplifying the amplitudes of seismic waves and increasing the shaking duration during earthquakes, and the $3 \mathrm{D}$ shape of the soft sedimentary cover, which may cause the seismic response to differ significantly from that of a 1D layer (e.g., trapped surface waves).

Involving geological data sets, the primary methods to evaluate site response consist of (1) using weak motion earthquake recordings by a local seismic network utilizing both the Standard Spectral Ratio (SSR) method and the Horizontal-to-Vertical (H/V) ratio method; (2) using measurements of seismic noise with the H/V ratio method [Nakamura 1989]; (3) deriving shear-wave velocity profiles using seismic array measurements.

In case of a strong impedance contrast between the soft soils and the bedrock, the horizontal-to-vertical spectral ratio determined from microtremors has shown to have a clear peak that is well correlated with the fundamental resonance frequency at soft soil sites
[Lachet and Bard 1994, Lermo and Chávez-García 1994, Field and Jacob 1995, Horike et al. 2001, Bard 2004]. For the single station noise measurements, once calibrated by comparison with the earthquake data results, most studies have shown that the peak amplitude of the microtremor ratio tends to underestimate the peak amplitude of earthquake spectral ratios with respect to a reference (i.e., bedrock) site (e.g., Bard [1999] lists 14 studies with this conclusion). Only a few studies claim rough agreement between the peak amplitude of the microtremor ratio and earthquake site-to-reference spectral ratios [Lermo and Chávez-García 1994, Mucciarelli et al. 2003, Molnar and Cassidy 2006]. In general, the site response shown by the earthquake site-to-reference SSR method is regarded the best approximation for engineering use, whereas $\mathrm{H} / \mathrm{V}$ spectral ratios from earthquakes and/or microtremors are regarded as providing the fundamental peak and a lower bound estimate of amplification for a soil site.

Additionally, the shear-wave velocity of near-surface materials is of fundamental interest for engineering and environmental purposes since this parameter characterizes the key properties for construction engineering and seismic response studies. Since direct measurements of shear-wave velocity suffer from high costs, non-invasive techniques have become a favorable alternative. One method for obtaining profiles of the shearwave velocity with depth involves jointly inverting the dispersive surface wave phase velocity and the $\mathrm{H} / \mathrm{V}$ spectral ratios [Parolai et al. 2005]. To extract the Rayleigh wave dispersion curves the spatial autocorrelation (SPAC) method [Aki 1957], which has been generalized to the extended spatial autocorrelation (ESAC) method proposed by Ohori et al. [2002], was used in our study. For deriving Rayleigh wave dispersion curves, microtremors are recorded with a small-scale array of geophones to evaluate the coherency spec- 
trum for multiple interstation separations. The receiver geometry may be chosen according to the local situation, but, in general, a good azimuthal coverage with irregular station spacing should be aimed for. By fitting the spatial-correlation function at each frequency to a Bessel function, which depends on the inter-station distances, the dispersion curve can be calculated.

This paper highlights some of those applications for site response evaluation as well as additional efforts specific to certain cities across Central Asia.

\section{Site response studies - some examples}

\subsection{Bishkek (Kyrgyzstan)}

Bishkek is the capital and the largest city of Kyrgyzstan having around 875,000 inhabitants. The city is located in the northwestern part of the Tien Shan Mountains in the central part of the Chu Basin, one of the largest depressions of northern Tien Shan, which extends about $50 \mathrm{~km}$ north-south and $150 \mathrm{~km}$ east-west [Bullen et al. 2001]. The shallowest part of the sedimentary cover is made up of poorly sorted, matrix supported, fan conglomerates with granitic boulders as large as $1 \mathrm{~m}$ in diameter. In the southern half of the Bishkek territory, alluvial gravels, rubble and sandy material (with a thickness ranging between 25 and $50 \mathrm{~m}$ ) constitute the shallowest geological layers. Below the urban area the Paleozoic basement depth is expected to generally decrease from the north $(\sim 1 \mathrm{~km})$ to the south-west $(\geq 3 \mathrm{~km})$.

In summer 2008, a temporary seismic network has been installed at 19 sites across the city using an EDL 24-bit digital acquisition system, equipped with a $1 \mathrm{~Hz}$ Mark L4C-3D sensor, recording continuously at 100 samples per second. The network recorded 56 events, including 50 crustal earthquakes with magnitudes between $M_{L} 1.6$ and $M_{W} 6.6$, occurring at distances between 35 and $1527 \mathrm{~km}$, as well as 6 deep earthquakes. From the weak-motion recordings of earthquakes, the first study of site response in Bishkek is documented in Parolai et al. [2010]. Using both H/V spectral ratios and standard spectral ratios with a bedrock reference site, a good correlation with the local soil conditions was found. In particular, a broad amplification is observed with clear distinct peaks between 0.1 and $0.2 \mathrm{~Hz}$ (increasing from south to north), $0.4 \mathrm{~Hz}$ and between 1 and $2 \mathrm{~Hz}$. It could be shown that such large amplification is due to both the layering of the Quaternary material and the impedance contrast within the tertiary layers. Strong impedance contrasts in combination with large peaks for stations located on the younger Quaternary sediments in the southern part of the urban area might be interpreted considering the additional ef- fect of converted waves on the observed ground motion. Such a complex nature of the wave field (with upgoing, down-going waves, and converted phases) due to the coarse, unconsolidated subsoil structure has been highlighted by results from a vertical array of accelerometers and numerical simulations of ground motion [Parolai et al. 2013].

As no information about the $S$-wave velocity of the material at shallow depths and the layering was available, four supplementary array measurements were carried out. The results indicate that the alluvial materials are quite stiff, particularly for the southern stations, with average $S$-wave velocities in the starting from nearly $600 \mathrm{~m} / \mathrm{s}$ in the shallowest layers (0-25 m depth). Along with the installation of the temporary network, single station measurements of seismic noise were carried out in the urban area covering the whole city at nearly 200 points using the same setup as described above. Seismic noise was recorded for about 30 minutes at each point. The data was split into $60 \mathrm{~s}$ window lengths, de-trended for base line corrections and tapered using a $5 \%$ cosine window at both ends. For the urban area, the fundamental frequency of the soil spans from around $0.3 \mathrm{~Hz}$ in the northern parts to $\sim 0.1 \mathrm{~Hz}$ in the south. This general decrease of the fundamental frequency from north to south is consistent with the geological structure of the basin, which shows an increase in the thickness of the sedimentary material towards the south [Bullen et al. 2001].

Using earthquakes recorded at a few selected sites for a relatively short amount of time and seismic noise data collected over a denser grid, Ullah et al. [2013] showed that the spatial resolution of ground motion variability in terms of SSRs can be significantly improved. Using a K-means algorithm, clusters of sites that display a similar response can be identified based on their similarity of the SSRs. Irrespective of the difference between the SSRs and seismic noise H/V spectral ratios for a single site, the variability in the noise $\mathrm{H} / \mathrm{V}$ spectral ratio is consistent with that of the SSRs. This analogy provides the opportunity for SSRs to be extended to sites where earthquake data is not available.

As can be seen in Figure 2, three clusters could be identified for Bishkek, which cover the northern part of the city, a central transition zone and the southern part. The clusters follow well the geological structure of the basin with the largest amplification mainly affecting the northern part of the urban area where lowest $S$-wave velocities can be found. The sudden increase of the amplification values corresponding to the geological contact between the different Quaternary materials is striking. The effect of the different Quaternary sediments, which are characterized by different values 


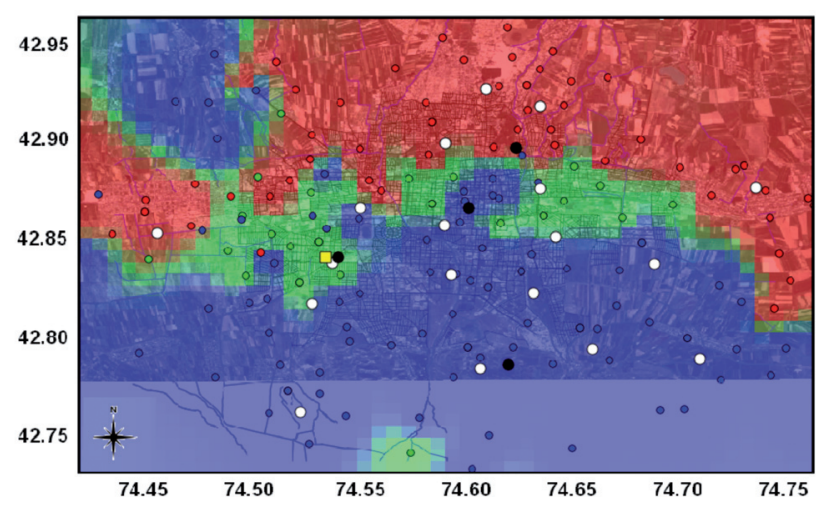

Figure 2. Temporary network (white dots) installed in Bishkek in summer 2008, array measurement sites (black dots) and location of the vertical array (yellow rectangle). The color-coded dots represent the location of the single station seismic noise measurement sites. Different colors represent the different clusters or groups.

of S-wave velocity, is responsible for the change in the site response amplitudes between the northern and the southern parts of the city around latitude 42.85 (Figure 2). Therefore, using seismological parameters alone, this approach allows an efficient zonation of the urban area with a high spatial resolution.

\subsection{Karakol (Kyrgyzstan)}

In eastern Kyrgyzstan, site response studies have been carried out in the city of Karakol ( 67,000 inhabitants), the fourth largest city in Kyrgyzstan and located near the eastern tip of Issyk-Kul in the foothills of the Terskey Ala-Too mountains on late Pleistocene sediments. Most of the settlements are located where the Karakol river enters the Issyk-Kul lake on thick terraces of young Pliocene conglomerates and debris deposits.
A temporary seismic network of 16 short-period sensors with the aforementioned set-up was installed in the city and neighboring settlements. The network operated continuously for more than three months in summer 2011. Around 80 events, local, regional and teleseismic, were recorded during this time. Moreover, single station seismic noise measurements were carried out at 34 sites across the city. Since the shear-wave velocity structure is hardly known in the city, three array measurements were also carried out in different parts of the city using all available instruments (Figure 3).

For the sites of the network the overall shape of the spectral ratios is similar only for low frequencies $(<1 \mathrm{~Hz})$ whereas in the high-frequency range the amplitudes of the spectral ratios show strong lateral variations with high amplitudes of around 7 to 9 in the northern part near lake Iyssk-Kul (Figure 3d). These sites are generally characterized by broad frequency band amplifications rather than well defined amplification peaks. In the southern parts of the city the amplitudes are significantly lower, being only around 1.5 to 3 . $\mathrm{H} / \mathrm{V}$ from noise analysis shows a flat response in the central and northern part of the city while some stations in the southern part show clear peak with large amplitude. On the other hand, since there is no significant amplification of the vertical motion in the highfrequency range (Figure 3c) the disparity between the SSRs and the H/V spectral ratios is rather low.

Such amplification as found here can potentially arise due to local $1 \mathrm{D}$ amplification as a result of the soil column below each station and due to locally generated surface waves which can provide additional mo-
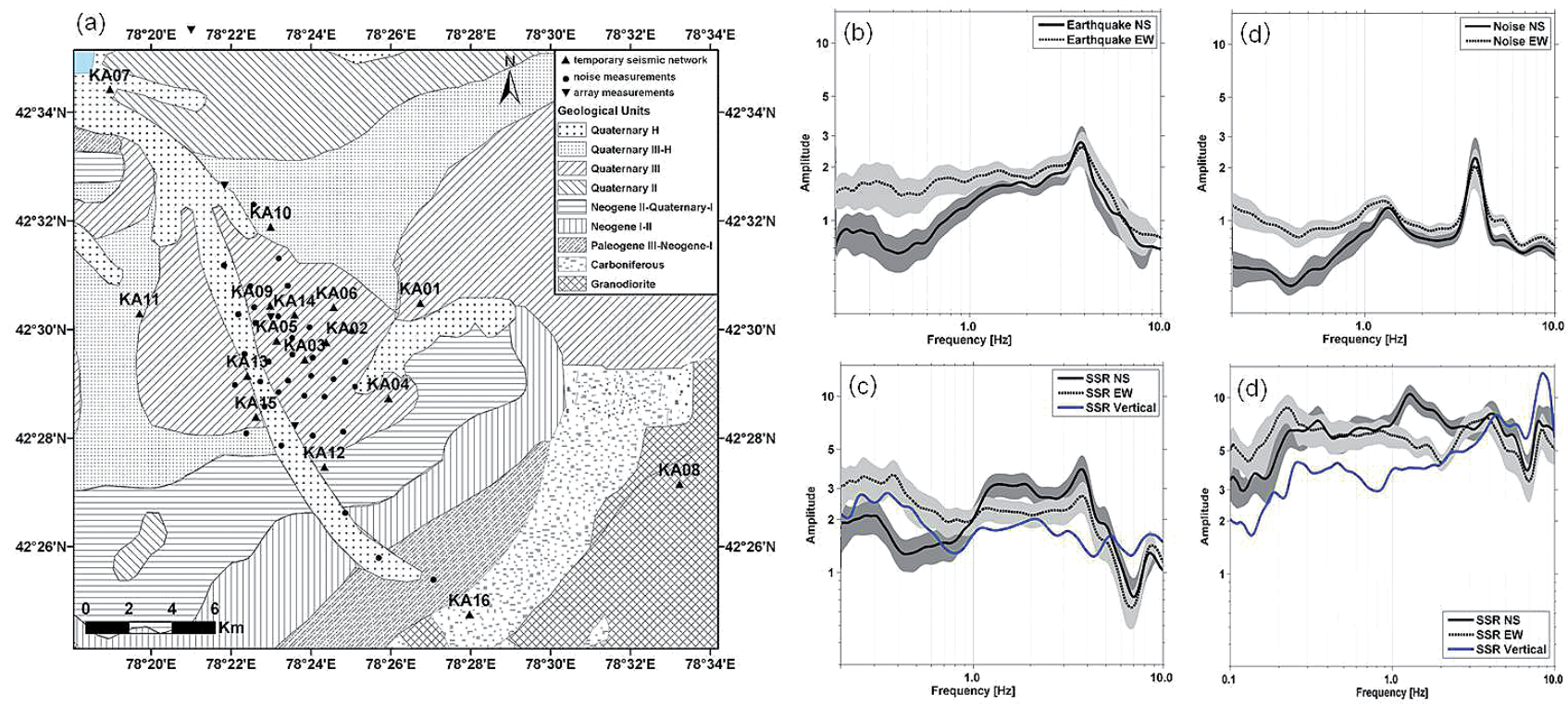

Figure 3. (a) Surface soil material for the city of Karakol. Seismic noise measurement sites (black dots) and installation sites of the temporary seismic network (black triangles) are indicated. (b) Horizontal-to-vertical spectral ratio plus/minus one standard deviation for earthquakes for station KA02. (c) H/V spectral ratio for noise at station KA02. (d) SSR for earthquakes for KA02 using KA08 located on bedrock as a reference. (d) SSR for earthquakes for KA07 using KA08 as a reference. 
tion in restricted frequency bands. In particular, the significant difference in the maximum amplitude between both horizontal components might argue against simple 1D site effects, following Chávez-García et al. [1999]. The net response at any site might therefore be seen as the result of all these two processes acting together, meaning that the higher amplification of the EW component in the low-frequency range might be indicative for more-dimensional effects and dipping layers at depth.

According to that, shear-wave velocities estimated from array analyses indicate rather low velocities of 200 to $400 \mathrm{~m} / \mathrm{s}$ in the uppermost $50 \mathrm{~m}$ in the northern parts of the city compared to 300 to more than $600 \mathrm{~m} / \mathrm{s}$ in the uppermost $50 \mathrm{~m}$ in the southern part. Such lateral variations are not unusual. However, detailed investigations may allow us in the future to understand better the role of the geological structures in the spatial variability of hazard, and therefore risk, in cities like Karakol.

\subsection{Naryn (Kyrgyzstan)}

Naryn is the provincial administrative center of the Naryn oblast in central Kyrgyzstan, with a population of 35,000. It is situated in a narrow valley along the main transport link from Kyrgyzstan to China on both banks of the Naryn river, one of the main head waters of the Syr-Darya. Geological and geomorphological evidence from remote sensing analysis and field observations (both in site and elsewhere in the Naryn valley) have identified lineaments crossing Quaternary alluvial terraces. The dominant geology at the site comprises superficial deposits of loess overlying river terrace gravels with unknown thickness. These overly bedrock of Lower Pliocene aged Naryn deposits [Djenchuraeva 2001]. In the city and its surroundings, Thompson et al. [2002] have identified several active faults, among them one of the largest recent faults of the Tien-Shan and known as the Central Naryn Fault, passing directly through the city.

Evidence from various studies for the site has shown that faulting has been an ongoing process throughout the Quaternary $(<2.4 \mathrm{Ma})$, including more recent epochs of the late Pleistocene and into the Holocene ( $<10,000$ years). Faults at outcrop provide evidence of successive earthquake events. The west-to-east trending faults are characteristic for the tectonic regime of crustal shortening in north-to-south direction [Arup and Partners Int. Ltd. 2012].

In summer 2013, a seismic network of 16 stations has been installed in the city. Altogether, more than 160 earthquakes have been recorded by the network. Complementarily, three array measurements and more than 130 single station noise measurements have been car- ried out (Figure 4). The data have been analyzed following the aforementioned procedures. Although the Naryn river valley is narrow $(\leq 1 \mathrm{~km})$, the fundamental frequency is rather low $\left(0.3 \leq f_{0} \leq 0.75 \mathrm{~Hz}\right)$ for all sites in the city and its surroundings, indicating an impedance contrast at great depths which is in line with the engineering-geological investigations of Ismailachunov [1975]. Such small lateral variations of the fundamental resonance frequency may be a result of $1 \mathrm{D}$ amplification effects in combination with fundamental or even higher modes of $S V$ or $S H 2$ D resonance, depending on the excited mode and on the position in the basin [see, e.g., Bard and Bouchon 1985, Roten et al. 2006]. Additionally, many measurement sites show peaks at higher frequencies between $2 \mathrm{~Hz}$ in the center of the river valley and $6.5 \mathrm{~Hz}$ at the edges. These peaks might be due to a shallow low-velocity layer or due to the excitation of local surface waves inside the basin due to lateral heterogeneities. As shown by Ermert et al. [2014], a layered model with distinct impedance contrasts will show mostly higher modes that are focused in the upper layers. In line with these findings, borehole logs have identified significant steps in elevation of top of bedrock as well (Naryn suite), increasing from west to east and having strong correlation with the $S$-wave velocity contrasts for the array sites.

The results indicate that of $2 \mathrm{D}$ and $3 \mathrm{D}$ effects are important for the seismic response of the Naryn valley. Additionally, as can be seen in Figure 4, the presence of a number of active faults across the city, where there is high probability of future surface fault rupture, requires seismic design taking into consideration near fault effects in the design strong-ground motion hazard levels. In addition to the seismic hazards, further geohazards arising from the Naryn river and further slope instabilities from alluvial fans and drainage channels from hillside to the river pose a further risk for the city of Naryn.

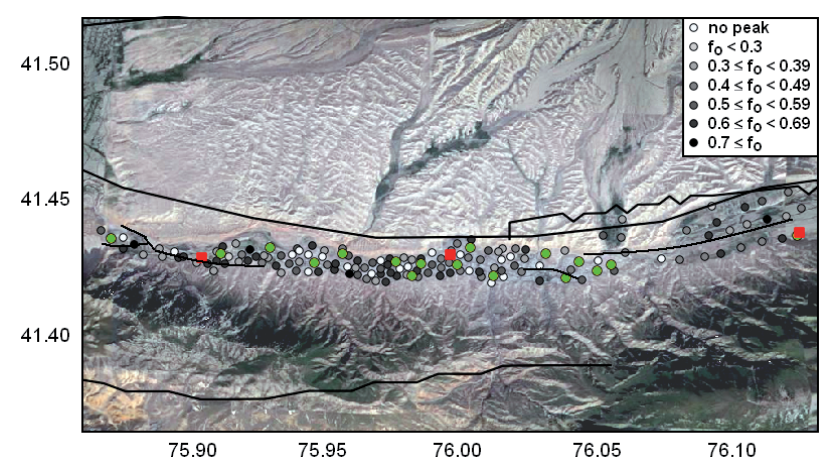

Figure 4. Fundamental frequency at single station measurement sites in Naryn. Temporary network (green dots) installed in summer 2013 and array measurement sites (red dots) are also shown. Black lines represent active faults [Arup and Partners Int. Ltd. 2012]. 


\subsection{Dushanbe (Tajikistan)}

Similar conditions also hold for the city of Dushanbe, the capital of Tajikistan. Situated at the confluence of two rivers, the Varzob and the Kafirnigan, present-day Dushanbe has around 650,000 inhabitants. The city is located in the central part of the Hissar valley, which has a sub-latitudinal extension and is limited to the north by the Hissar Range and to the south by the Babatag and Rangon ridges. In the territory of the city and its southern peripheral parts, thick deposits of Quaternary deposits are widespread. They tend to form accumulated terraces of ancient and modern valleys, also covering the lower parts of watersheds and slopes of ridges. These Quaternary sediments are interleaved by alluvial and diluvial sediments and their paragenetic combinations [Zodotarow et al., undated]. The thickness of the Quaternary deposits can be up to several hundred meters in the central part of the valley, but it decreases to a few meters at the foothills and in areas where the bedrock outcrops.

The entire area is facing a high level of hazard due to its closeness to two main fault systems. Hence, already beginning of the 1950s detailed macroseismic investigations were carried out [Medvedev 1952]. Thereon, Nazarov and Nechaev [1953] published one of the very first microzonation maps for Stalinabad (the former name of Dushanbe). In the 1960s, the city expanded rapidly, mainly in southern direction but also up the slopes of the fringing mountain ranges in the northeast, i.e., on geologically unfavourable material. Since seismic hazard in Dushanbe is related not only to shallow local earthquakes but also to deep focus distant earthquakes, two different zoning maps were proposed for the town, one for buildings with less than 5 stories and another one for taller buildings [Cohen et al. 1975].

For updated site response investigations a dense temporary seismic network covering 72 sites in the entire built-up area (Figure 5; Pilz et al. [2013]) has been installed between spring and autumn 2012. Moreover, noise recordings were collected by means of 37 single station noise measurements as well as four micro-array configurations. From the continuous data streams of the network, the recordings of 292 earthquakes $(3.2 \leq \mathrm{M} \leq 7.2)$ were extracted.

The spectral ratios at all investigated sites show a clear narrow peak or even amplification over a broad frequency range. In particular, stations located on loess deposits both in the eastern and western parts of the city are characterized by amplification in a broad range from $\sim 1$ to $\sim 10 \mathrm{~Hz}$. Since the soil conditions are expected to vary throughout the city with complicated layers and lenses of buried soils [Negmatullaev et al. 1999] such broad H/V peaks can be linked to sites with strong lateral heterogeneities and large near-surface

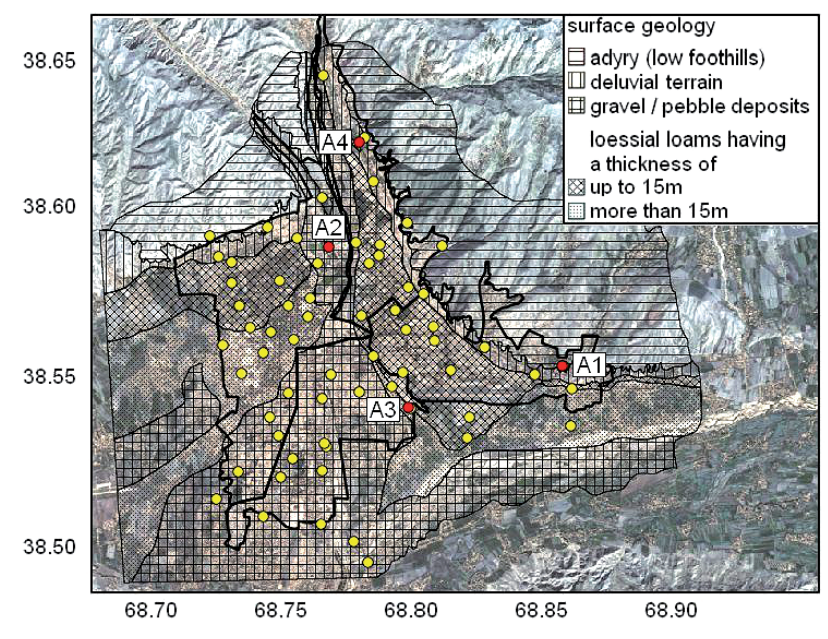

Figure 5. Surface soils [Zodotarow et al., undated] for the city of Dushanbe. Yellow dots represent installation sites of the temporary seismic network. Red dots represent array measurement sites and black dots represent noise measurement sites. Network installation sites and sites of array measurements mentioned in the text are labeled. The thick black lines are administrative borders of the city.

shear-wave velocity contrasts [Woolery and Street 2002]. On the other hand, for the southern parts, where the gravel and pebble sediments are expected to be rather thick, large heterogeneities for the shallow structures have been found [Pilz and Parolai 2014]. Also the amplitudes of the SSRs take a high value of $\sim 5$, exposing the settlements there to a high level of hazard.

In addition to the spectral amplification pattern derived by the seismic network, direct observations of local $\mathrm{S}$-wave velocity-depth profiles are a key factor in seismic hazard assessment. Considering the high geological heterogeneity characterizing the investigated area, four arrays at sites with different surficial geology (see Figure 5) highlight strong lateral variations. As can be seen in Figure 6, array A3, located on gravel deposits overlain by a thin layer of loess, shows rather high $\mathrm{S}$-wave velocities of almost $500 \mathrm{~m} / \mathrm{s}$ below $10 \mathrm{~m}$ depth which increase up to more than $1000 \mathrm{~m} / \mathrm{s}$ for the deepest parts. On the other hand, for A1 and A4, located on diluvial material, the $S$-wave velocities in the shallow layers are significantly lower (around $300 \mathrm{~m} / \mathrm{s}$ down to $45 \mathrm{~m}$ for A4). For A1, also the deeper layers down to $100 \mathrm{~m}$ clearly show lower velocities, indicating a broad amplification pattern. The deep saturated low-velocity soil layers in the north-west of Dushanbe around array A4 seem to be particularly prone to non-linear site amplification [Ni et al. 1997, Hartzell et al. 2004]. Moreover, due to the potential for loess soil around A3 and A4 to experience subsidence deformation, this fact will also negatively influence the technical conditions of buildings and structures, making them highly vulnerable under seismic excitations. Therefore, such highly detailed site information obtained by the dense seismic network is crucial when assessing seismic hazard and risk. 

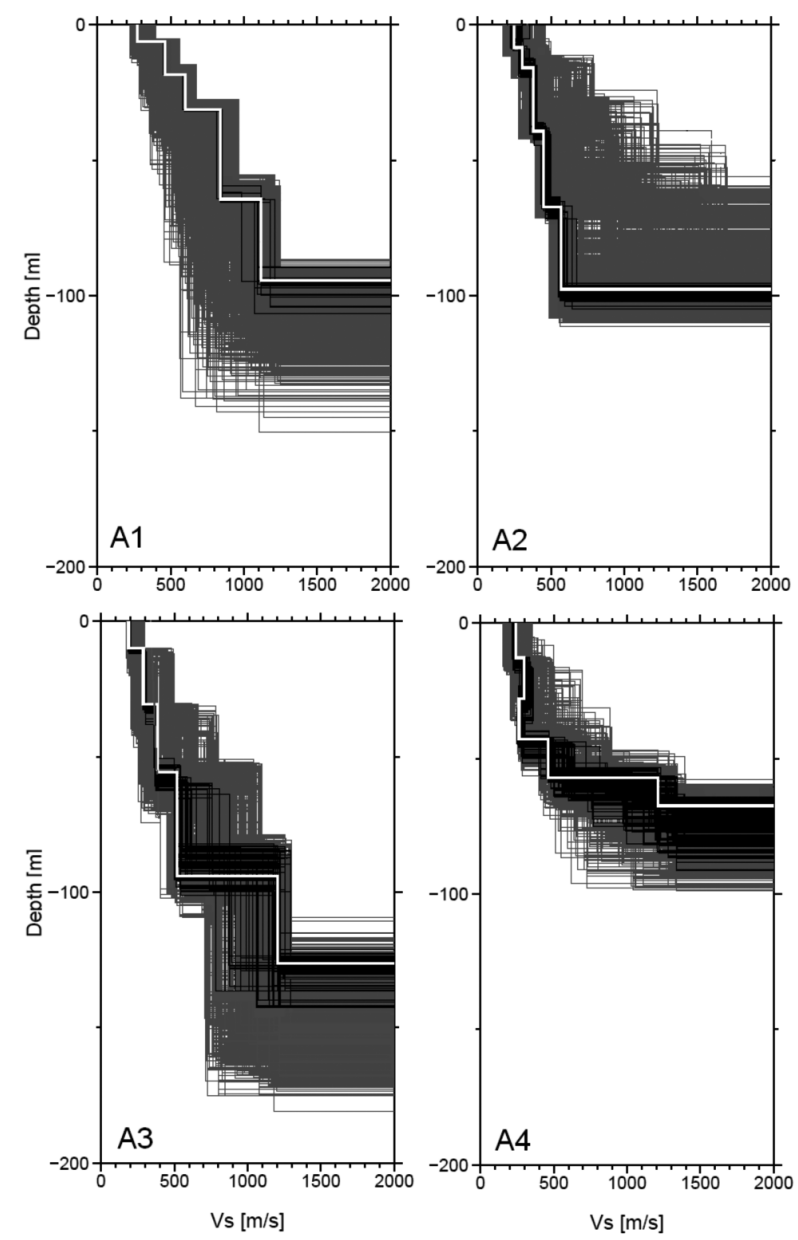

Figure 6. Shear-wave velocity profiles for array measurement sites in Dushanbe shown in Figure 5. Thin gray lines show all tested models. The white line represents the minimum cost model and the black lines indicate all models lying inside the minimum cost $+10 \%$ range.

\subsection{Khorog (Tajikistan)}

Khorog is the administrative centre of the GornoBadakhshan autonomous oblast in Tajikistan. It is located in the southwestern region of the oblast in a narrow valley some $2000 \mathrm{~m}$ above sea level where the Gunt river enters the Panj river. The valley is filled with Holocene deposits which are expected to have a large thickness as the slope of sharp-edged canyon suggests. In summer 2012 a network of 12 short period sensors was installed in the city of Khorog which operated continuously for more than 3 months. Additionally, two array measurements have been made. Around 100 events were recorded during this time of whose many occurred at local and regional distances. Following standard analysis procedures, earthquake $\mathrm{H} / \mathrm{V}$ spectral ratio have been calculated (see Figure 7). However, no SSR analysis could be carried out due to the unavailability of a proper reference site.

Most of the network sites do not only show a single peak for the $\mathrm{H} / \mathrm{V}$ spectral ratios but amplification is further found over broad ranges in the intermediatefrequency range. The fundamental frequency of $\sim 1 \mathrm{~Hz}$ might be associated with a deep impedance contrast to the bedrock while the first higher mode $\sim 5 \mathrm{~Hz}$ might be linked to a shallow impedance contrast at the gravel layer. As shown in Figure 7, the S-wave velocity-depth profiles at the array sites also suggest the presence of two impedance contrasts at depths of around $50 \mathrm{~m}$ and $80 \mathrm{~m}$.

Interestingly, since the interstation distance between the stations of the temporary network is rather small (on average less than $1 \mathrm{~km}$ ) a clear trend can be identified for the peak amplitudes. Whereas the H/V spectral ratios around the fundamental frequency for the stations in the west do not show high amplitudes, much higher values (and small standard deviations) can be found for the H/V spectral ratios at the eastern sites. This might indicate a comparatively higher impedance contrast at depth in the east. A possible explanation for this pronounced difference might be a higher compaction of the sediments in the eastern parts of the studied area.

On the other hand, similar to the situation in Naryn, more-dimensional effects are also likely to occur in the narrow valley of the Gunt river around Khorog. Whereas the fundamental resonance frequency varies between $0.8 \mathrm{~Hz}$ and $1.8 \mathrm{~Hz}$, no significant lateral variations can be observed for the frequency of the first higher mode. Peaks in observed Fourier spectral ratios also suggest that edge-generated surface waves are contributing to amplification at higher frequencies. So, in this case, the interference of surface waves with vertically propagating waves might give rise to the evolution of a $2 \mathrm{D}$ resonance pattern for such deep valleys [Bard and Bouchon 1980, Roten et al. 2006].

Remarkably, rather high amplitudes for the $\mathrm{H} / \mathrm{V}$ spectral ratios, which provide only a lower bound in terms of site amplification, are found for the eastern parts of Khorog. This indicates that high amplification over a broad frequency range might occur. Remarkably, the area of high amplification corresponds exactly to the zone in which building densification and the completion of the new university is expected in future, therefore exposing the structures to a high level of hazard. Preventative measures are therefore highly indispensable.

\subsection{Tashkent (Uzbekistan)}

Tashkent, the largest city of Central Asia and the capital of Uzbekistan, presently offers a home for more than 2.1 million people. The level of hazard is high since more than 70 events with magnitudes greater than or equal to magnitude 4.5 are known to have affected the region since 1868. The nature of Tashkent is determined by its location in the foothills of western Tien Shan on the spacious right bank of the Chirchik river in the transition zone to the Turan platform. In 
addition to Chirchik river, the city's territory includes the complicated system of artificial and natural channels. Below the city large loess deposits, including loam and sand over flood deposits of the Chirchik river, can be found [Mavlyanov 1958, Rozycki 1991]. The soil is moderately compressible and rather inhomogeneous, requiring consideration of irregular settling since it has not yet settled. The possibility of liquefaction of the saturated sandy loams is given.

In 2009 a small network of five short-period sensors with the aforementioned set-up was installed in the city and neighboring settlements. The network operated continuously for three months. Around 30 events,

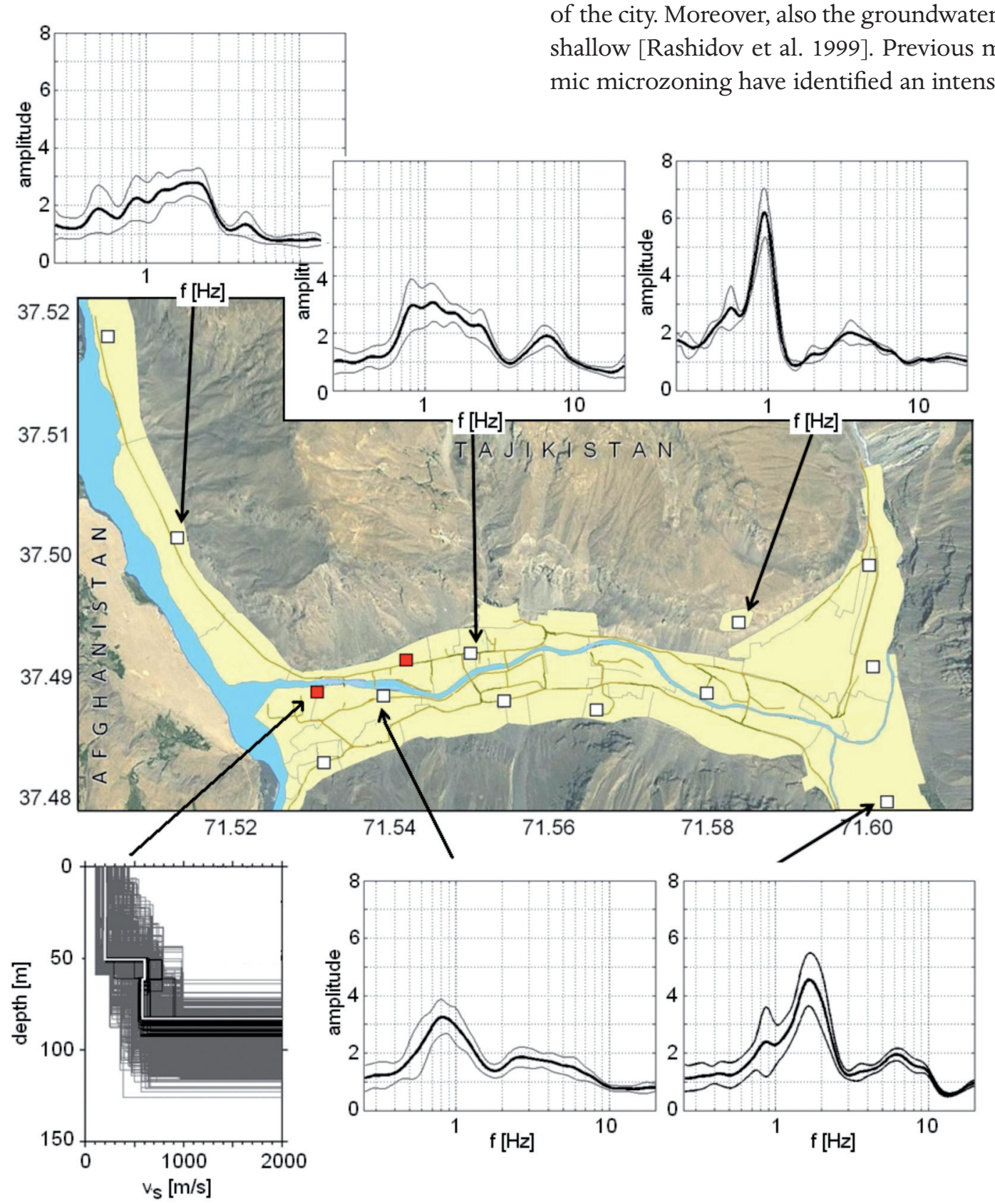

local, regional and teleseismic, were recorded during this time. Moreover, single station seismic noise measurements were carried out at a few sites across the city. The data have been analyzed following standard procedures. As a result, three different patterns of $\mathrm{H} / \mathrm{V}$ spectral ratios, corresponding roughly to the three types of soils in the urban area, can be found. Measurement sites in the northern and north-western part of the city are characterized by large amplitudes around 5 at a fundamental frequency of $\sim 3 \mathrm{~Hz}$. Moreover, a first higher mode $\sim 7 \mathrm{~Hz}$ can be reliably identified for most sites. Loess with a thickness of about 30 to $40 \mathrm{~m}$ on the top of a layer of marls is found in this area of the city. Moreover, also the groundwater level is very shallow [Rashidov et al. 1999]. Previous maps of seismic microzoning have identified an intensity of IX for

Figure 7. Network layout (white dots) and array measurement sites (red dots) in the city of Khorog. Horizontal-to-vertical spectral ratios for earthquakes plus/minus one standard deviation are shown for representative stations. For the western array measurement site the shearwave velocity profile is shown. Thin gray lines show all tested models. The white line represents the minimum cost model and the black lines indicate all models lying inside the minimum cost $+10 \%$ range. 
the northern and western parts [Kasymov 1984].

In the south-eastern parts of the city thick (250 to $300 \mathrm{~m}$ ) layers of alluvial gravel deposits terraces can be found with varying degree of sand content. This area is covered only by a thin $(\sim 5 \mathrm{~m})$ layer of loess. H/V spectral ratios indicate a fundamental frequency of $2.5 \mathrm{~Hz}$ with a significant lower level of amplification mainly due to the large compaction. For this part of the city previous investigations have assigned an intensity of VIII [Kasymov 1984]. However, one has to keep in mind that the $\mathrm{H} / \mathrm{V}$ spectral ratios might only provide a lower bound estimate in terms of site amplification. Also during the 1966 event lower intensity values have been observed for the southern parts whereas in the center and in the northern parts the intensity was higher [Nurmagambetov and Ismailov 1994]. Between these two extreme values, sites along the Chirchik river in the eastern part of the city show an intermediate behavior. Three frequencies of resonance $(\sim 3 \mathrm{~Hz}, \sim 5 \mathrm{~Hz}$ and $\sim 7.5$ $\mathrm{Hz})$ can be identified. In this part of the city, thick loess layers on top of a layer of boulders can be found. Considering these specific site conditions is highly advisable when as currently new methods for building design and construction control in Uzbekistan are on the way.

\subsection{Almaty (Kazakhstan)}

Almaty, formerly known as Alma-Ata, is the largest city in Kazakhstan having around 1.5 million inhabitants, and was the country's capital until 1997. Despite losing its status as the capital to Astana, Almaty remains the major commercial and cultural centre of Kazakhstan. The city is located near the northern flanks of the Alatau range on a layer of friable deposits of the Almaty depression. In addition, the city contains several faults which have not been associated with any previous event but might have the potential to generate a large event. The central part of Almaty is composed of rock covered with sandy and loamy deposits. In the northern part of the city, the soil includes thick layers of sand. During the last 150 years the city was destroyed several times by strong earthquakes, most recently in 1911 by the Kemin event. The Agency for Emergencies of the Republic of Kazakhstan estimated that for a similar event the total number of people injured or affected would be 300,000 . Of these, some 75,000 people would likely be killed. Approximately one third of all residential buildings in Almaty would be destroyed. As calculated, the consequences of such an earthquake would be on the scale of a national disaster.

Therefore, research activities on earthquakes started rather early and were increased significantly in the 1970 s during the installation of strong motion network in Kazakhstan. Besides the regional aspects also a local network at ten sites located in different engineering-geological conditions in the central districts of Almaty was operating since the early 1980s. Supplementary, 16 weak motion instruments (Guralp CMG-3ESP broadband sensors) have been installed in summer 2014, partially co-located but also extending the network coverage in the outskirts of the city (Figure 8). Moreover, using the same equipment, around 220 measurements of seismic noise have been carried out in the urban area with recording durations not less than 60 minutes.

As can be seen in Figure 8, strong amplification occurs at low frequencies around 0.1 to $0.2 \mathrm{~Hz}$ due to the strong impedance contrast between the Paleozoic sediments and the bedrock. Such amplification effects at low frequencies are particularly dominant in the central and north-western parts of the city. The lowest fundamental resonance frequencies around $0.08 \mathrm{~Hz}$ are found for the central-eastern parts around VRG (see Figure 8), where the thickness of the sedimentary cover with Paleozoic and more recent deposits reaches a thickness of up to $3.7 \mathrm{~km}$ [Shatsilov 1989]. Here, the soils are characterized by soft clay deposits and sandy loams, giving rise to high amplification values. Already in the past this area has been characterized as the most hazardous part of the city with a maximum intensity of X assigned to this area [Medvedev 1994]. A further clear peak in the range between 0.5 and $1 \mathrm{~Hz}$, which might be interpreted as the first higher mode, due to a more shallow impedance contrast can be found for all measurement sites. Additionally, peaks at frequencies higher than $10 \mathrm{~Hz}$ can be identified for all stations in the central part and the northern districts of the city where soils with low stiffness (sandy loams and sands of different coarseness) are predominant. Thin layers of covering formation (thickness 5 to $20 \mathrm{~m}$ ) are predominant there. Amplification in this frequency range might be particularly hazardous since it might coincide with the resonance frequency of prevalent single family houses. Altogether, such high amplification values on the one hand as well as high-frequency amplification on the other hand with significant lateral variations indicate a high level of hazard and put serious constraints on any design regulations in the future.

\section{Summary}

All investigations carried out in this work showed that site effects have a considerable influence on earthquake ground motion in the cities of Central Asia. This observation is consistent with the relatively variable damage distribution observed during previous events. The H/V spectral ratio technique, once validated by comparing its results with those obtained using earthquake recordings, can be used as a fast tool for micro- 


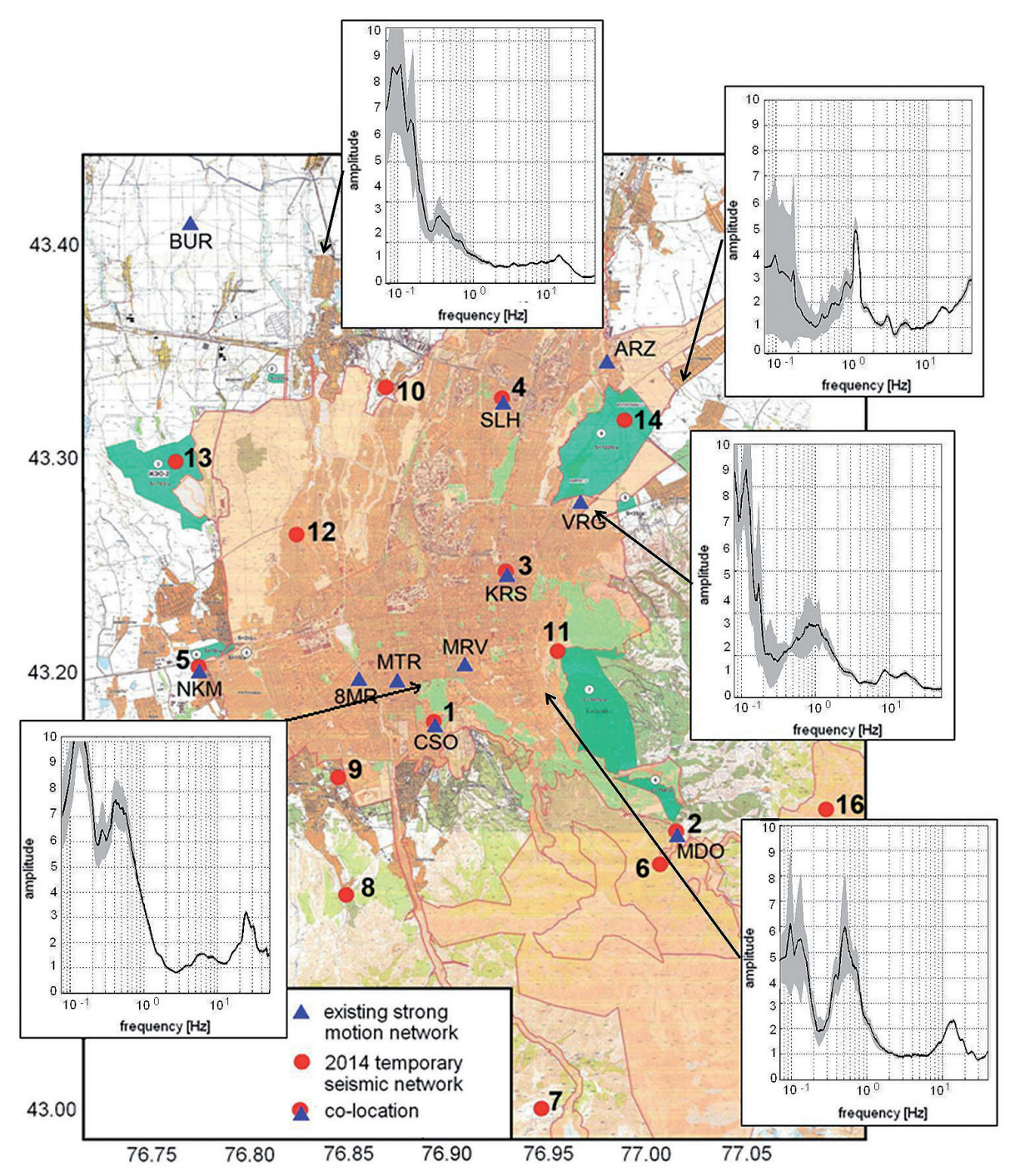

Figure 8. Network layout indicating the location of the existing strong motion stations (blue triangles) and weak motion stations (red dots) in the city of Almaty. The embedded images show the noise $\mathrm{H} / \mathrm{V}$ spectral ratio plus/minus one standard deviation for representative sites in the city. The reddish color shows the actual administrative border of the city. The greenish areas will be incorporated in the future.

zonation studies in urban environments. There are a number of reasons for this, including the ease with which ambient noise measurements can be collected and processed, array methodologies that provide shearwave velocity measurements and images of the subsurface geology in urban areas, and a wealth of geological and geotechnical data that has been compiled in a number of cities in Central Asia. However, the problem of quantitative account for nonlinear phenomena in soft and saturated soils when estimating seismic hazard is still to be resolved.

Combining the outlined results with further information on the geological layering and its properties might provide a precise estimate of the expected ground motion. New approaches like cluster analysis can allow an even faster and more efficient microzonation with a higher spatial resolution by using seismological parameters alone. Hence, when the soil properties in terms of the average $S$-wave velocity of the uppermost $30 \mathrm{~m}\left(\mathrm{v}_{\mathrm{s}}^{30}\right)$, assessed from seismic noise array analyses, and response spectral ratios from earthquake recordings, are adequately known, explicit site-specific consideration of the soil response in probabilistic seismic hazard assessment can provide soil-surface-hazard estimates which are more precise than those from simple attenuation equations for generic soil conditions (see Ullah et al. [2015], this issue). The results highlight the under-estimation of seismic hazard relying only on rock site conditions or $\mathrm{v}_{\mathrm{s}}^{30}$.

Moreover, results from site response studies, when combined with further seismic parameters like peak ground acceleration (PGA) and information of the building response from engineering studies (see Bindi et al. in this issue), are also critical to account both for the urban risk. Since design seismic forces depend on both the PGA and the shape of the normalized response spectra which are dictated by the national building codes. Therefore, instead of using standard response spectra, it might be necessary to construct site-specific spectra since a single design curve and a single seismicity coef- 
ficient (PGA value) for generalized soil conditions might not be adequate for the entire territory of a city.

\section{Conclusions}

Worldwide future earthquakes will have more urban centers and exposed valuable elements to target. Especially in all Central Asia, the strong tendency towards urbanization will create an even higher potential for economic and human losses. However, we can also be better armed in assessing the physical and socioeconomic impact of earthquakes by a proper allocation of resources towards the mitigation of these impacts. The extensive research being carried out in the frame of EMCA on the development of earthquake risk assessment methodologies guides our expectation in the future. To this regard, site effect studies have been carried out in several strategic towns in Central Asia. Depending on the environmental conditions, several city specific issues in terms of site amplification could be identified. In the end, a reliable evaluation of the seismic risk on a local scale, together with a realistic assessment of the assets that are exposed to seismic hazard and their structural vulnerability, can, therefore, be used to undertake proper mitigation actions and to promptly and efficiently react to a potential catastrophic event. The results are expected to be shared with the local stakeholders to be used for updating normative documents and building codes, for modeling destructive seismic events and for designing seismic resistant constructions and also to increase the awareness of the general public. The findings are also expected to be used by the state authorities for emergency situations to assess the risk and to create system for timely warning and response to emergencies.

Acknowledgements. We are very grateful for the collaboration and support given to us during the survey measurements and the data collection by many people in Central Asia. We thank the technical staff of the Central Asian Institute for Applied Geosciences (CAIAG) in Bishkek, of the Institute of Seismology of the Academy of Sciences of the Kyrgyz Republic in Bishkek, of the Institute of Geology, Earthquake Engineering and Seismology of the Academy of Sciences of the Republic of Tajikistan, of the Aga Khan Development Network Disaster Risk Management Initiative and of FOCUS Tajikistan in Dushanbe and of the Institute of Seismology of the Academy of Sciences of the Republic of Kazakhstan in Almaty for their help during the field work. Instruments were provided by the Geophysical Instrumental Pool Potsdam (GIPP) and by the CAIAG.

\section{References}

Aki, K. (1957). Space and time spectra of stationary stochastic waves with special reference to microtremors, Bulletin of Earthquake Research Inst. Tokyo Univ., 35, 415-456.

Andreev, E.M., L.E. Darskii and T.L. Kharkova (1993)
Naselenie Sovetskogo Soiuza, 1922-1991, Nauka, Moscow, Russia (in Russian).

Arup and Partners Int. Ltd. (2012). University of Central Asia Naryn - Geomorphology and seismic assessment report, report 123620, London, UK.

Bard, P.Y., and M. Bouchon (1980). The seismic response of sediment-filled valleys. Part 2. The case of incident P and SV waves, B. Seismol. Soc. Am., 70, 1921-1941.

Bard, P.-Y., and M. Bouchon (1985). The two-dimensional resonance of sediment-filled valleys, B. Seismol. Soc. Am., 75, 519-541.

Bard, P.-Y. (1999). Microtremor measurements: A tool for site effect estimation?, Proc. Int. Symp. on the Effects of surface geology on seismic motion, 12511279.

Bard, P.-Y. (2004). Effects of surface geology on ground motion: Recent results and remaining issues, Proc. 10th Conf. Earthq. Eng., 305-325.

Bindi, D., T. Boxberger, S. Orunbaev, M. Pilz, J. Stankiewicz, M. Pittore, I. Iervolino, E. Ellguth and S. Parolai (2015). On-site early-warning system for Bishkek (Kyrgyzstan), Annals of Geophysics, 58 (1), S0112; doi:10.4401/ag-6664.

Bullen, M.E., D.W. Burbank, J.I. Garver and K. Abdrakhmatov (2001). Late Cenozoic tectonic evolution of the northwestern Tien Shan: new age estimates for the initiation of mountain building, Geol. Soc. Am. Bull., 113, 1544-1559.

Bune V.I., and G.P. Gorshkov (1980). Seismic zonation of USSR, Nauka, Moscow, 307 pp. (in Russian).

Chávez-García, F.J., W.R. Stephenson and M. Rodríguez (1999). Lateral propagation effects observed at Parkway, New Zealand. A case history to compare 1D versus 2D site effects, B. Seismol. Soc. Am., 89, 718-732.

Cohen, L.A., J.M. Mirzobaev, G.O. Oripov and A. Romanov (1975). Map of the seismic zonation of Dushanbe, Soviet Academy of Science, Moscow (in Russian).

Djenchuraeva, A.V. (2001). Stratigraphy and lithology of Paleozoic Aksai and Naryn basins' mountain frame, Archives of the State Geological Agency of the Kyrgyz Republic, Bishkek, Kyrgyzstan (in Russian).

Erdik, M., T. Rashidov, E. Safak and A. Turdukulov (2005). Assessment of seismic risk in Tashkent, Uzbekistan and Bishkek, Kyrgyz Republic, Soil Dyn. Earthq. Eng., 25, 473-486.

Ermert, L., V. Poggi, J. Burjánek and D. Fäh (2014). Fundamental and higher two-dimensional resonance modes of an Alpine valley, Geophys. J. Int. 198, 795811.

Field, E.H., and K.H. Jacob (1995). A comparison and test of various site-response estimation techniques, 
including three that are not reference-site dependent, B. Seismol. Soc. Am., 85, 1127-1143.

GeoHazards International (1996). Lessons for Central Asia from Armenia and Sakhalin: Strategies for urban earthquake risk management for the Central Asian Republics, Central Asian workshop urban for earthquake risk management and strategies for Central Asian republics, Almaty, Kazakhstan.

Gorshkov, G.P. (1937). The seismic map of the USSR, In: Bolshoy Sovietsky Atlas Mira, 93, Moscow, USSR (in Russian).

Hartzell, S., L.F. Bonilla and R.A. Williams (2004). Prediction of nonlinear soil effects, B. Seismol. Soc. Am., 94, 1609-1629.

Horike, M., B. Zhao and H. Kawase (2001). Comparison of site response characteristics inferred from microtremors and earthquake shear waves, B. Seismol. Soc. Am., 91, 1526-1536.

Ismailachunov, S.I. (1975). Engineering-geological map of Naryn, Soviet Academy of Science, Moscow (in Russian).

Kasymov, S.M. (1984). Seismic microzonation map of Tashkent, Nauka, Moscow, USSR.

Kyurskeyev, A., A. Nurmagambetov, A. Sydykov, N.N. Mikhailova and V.I. Shatsilov (1993). Detailed Seismic Zoning of Almaty Industrial Area, Novosti Nauki Kazakhstana, 1, Alma-Ata, Kazakhstan.

Lachet, C., and P.Y. Bard (1994). Numerical and theoretical investigations on the possibilities and limitations of Nakamura's technique, J. Phys. Earth, 42, 377-397.

Lermo, J., and F.J. Chávez-García (1994). Are microtremors useful in site response evaluation?, B. Seismol. Soc. Am., 84 1350-1364.

Lutz, W. (2010). Emerging population issues in Eastern Europe and Central Asia. Research Gaps on Demographic Trends, Human Capital and Climate Change, UNFPA, New York, USA.

Mavlyanov, G.A. (1958). Genetic types of loesses and loess-like rocks of the central and southern parts of Central Asia and their geological engineering properties, Uzbekistan Academii Science Press, Tashkent, Uzbek SSR, 649 pp. (in Russian).

McGuire, R.K. (2004). Seismic hazard and risk analysis, EERI monograph MNO-10, Earthquake Engineering Research Institute, Oakland, California.

Medvedev, S.V. (1952). Evaluation of seismic intensity as a function of ground conditions, Geological Institute of the Soviet Academy of Science, 14, 29-52 (in Russian).

Medvedev, S., W. Sponheuer and V. Kárník (1964). Neue seismische Skala, 7. Tagung der europäischen seismologischen Kommission, In: Veröffentlichungen des Instituts für Bodendynamik und Erdbebenforschung, 77, 69-76, Deutsche Akademie der Wissenschaften (ed.), Berlin.

Medvedev, S.V. (1994). Construction of Almaty and surrounding territories taking into account seismic microzoning, Alma-Ata, Kazakhstan.

Mikhailova, N. (1996). Seismic hazard in quantity characteristics of strong ground motions (on the example of Almaty), PhD thesis, University of Almaty.

Molnar, P., and P. Tapponnier (1975). Cenozoic tectonics of Asia: Effects of a continental collision, Science, 189, 419-426.

Molnar, S., and J.F. Cassidy (2006). A comparison of site response techniques using weak-motion earthquake and microtremors, Earthq. Spec., 22, 169-188.

Mucciarelli, M., M.R. Gallipoli and M. Arcieri (2003). The stability of the horizontal-to-vertical spectral ratio of triggered noise and earthquake recordings, B. Seismol. Soc. Am., 93, 1407-1412.

Nakamura, Y. (1989). A method for dynamic characteristics estimation of subsurface using microtremor on the ground surface, Quart. Rep. Railway Tech. Res. Inst., 30, 25-33.

Nazarov, A.G., and B.A. Nechaev (1953). Seismic microzonation map - the administrative area of Stalinabad, Soviet Academy of Science, Moscow (in Russian).

Negmatullaev, S., A. Ischuk and Y. Potekhin (1999). Seismic hazard and building vulnerability in Tajikistan, in: Seismic hazard and building vulnerability in postSoviet Central Asian republics, S. King, V.I. Khalturin, B.E. Tucker (eds.), Kluwer Academic Publishers, Dodrecht, Netherlands.

Ni, S.D., R.V. Siddharthan and J.G. Anderson (1997). Characteristics of nonlinear response of deep saturated soil deposits, B. Seismol. Soc. Am., 87, 342-355.

Nurmagambetov, K., and V. Ismailov (1994). Main components of engineering geologic conditions determining the seismic intensity of the territory and their self-descriptiveness under seismic micro-zoning accomplishment. Forecast of seismic danger in Uzbekistan, Uzbek. Academy of Science, 1, Tashkent, Uzbekistan.

Nurmagambetov, A., N. Mikhailova and W. Iwan (1999). Seismic hazard of the Central Asia region, Springer, Berlin, 1-43.

Ohori, M., A. Nobata and K. Wakamatsu (2002). A comparison of ESAC and FK methods of estimating phase velocity using arbitrarily shaped microtremor arrays, B. Seismol. Soc. Am., 96, 2323-2332.

Parolai, S., M. Picozzi, S.M. Richwalski and C. Milkereit (2005). Joint inversion of phase elocity dispersion and $\mathrm{H} / \mathrm{V}$ ratio curves from seismic noise recordings 
using a genetic algorithm, considering higher modes, Geophys. Res. Lett., 32, L01303; doi:10.1029 / 2004 GL021115.

Parolai, S., S. Orunbaev, D. Bindi, A. Strollo, S. Usupaev, M. Picozzi, D. Di Giacomo, P. Augliera, E. D’Alema, C. Milkereit, B. Moldobekov and J. Zschau (2010). Site effects assessment in Bishkek (Kyrgyzstan) using earthquake and noise recording data, B. Seismol. Soc. Am., 100, 3068-3082.

Parolai, S., D. Bindi, S. Ullah, S. Orunbaev, S. Usupaev, B. Moldobekov and H. Echtler (2013). The Bishkek vertical array (BIVA): acquiring strong motion data in Kyrgyzstan and first results, J. Seismol., 17, 707-719.

Penuel, K.B., and M. Statler (2010). Encyclopedia of disaster relief, SAGE, Thousand Oaks, USA, 984 pp.

Pilz, M., D. Bindi, T. Boxberger, F. Hakimov, B. Moldobekov, S. Murodkulov, S. Orunbaev, M. Pittore, J. Stankiewicz, S. Ullah, F. Verjee, M. Wieland, P. Yasunov and S. Parolai (2013). First steps toward a reassessment of the seismic risk of the city of Dushanbe (Tajikistan), Seismol. Res. Lett., 84, 10261038.

Pilz, M., and S. Parolai (2014). Statistical properties of the seismic noise field: influence of soil heterogeneities, accepted for publication in Geophys. J. Int.

Rashidov, T., L. Plotnikova and S. Khakimov (1999). Seismic hazard and building vulnerability in Uzbekistan, In: S. King, V.I. Khalturin and B.E. Tucker (eds.), Seismic hazard and building vulnerability in post-Soviet Central Asian republics, Kluwer Academic Publishers, Dodrecht, Netherlands.

Roten, D., D. Fäh, C. Cornou and D. Giardini (2006). Two-dimensional resonances in Alpine valleys identified from ambient vibration wavefields, Geophys. J. Int., 165, 889-905.

Rozycki, S.Z. (1991). Loess and loess-like deposits, Ossolineum Publishing House, 187, Polish Academy of Science, Wroclaw, Poland.

Shatsilov, V.I. (1989). Survey technique for seismic hazard assessment, Nauka, Alma-Ata, Kazakh SSR, 208 pp.

Thompson, S.C., R.J. Weldon, C.M. Rubin, K. Abdrakhmatov, P. Molnar and G. Berger (2002). Late Quaternary slip rates across the central Tien Shan, Kyrgyzstan, Central Asia, J. Geophys. Res., 107, ETG7-1-ETG7-32.

Trifonov, V.G., O.V. Soboleva, R.V. Trifonov and G.A. Vostrikov (2002). Recent geodynamics of the Alpine-Himalayan collision belt, Transactions of the Geological Institute RAS, 541, 224 p. (in Russian).

Ullah, S., D. Bindi, M. Pittore, M. Pilz, S. Orunbaev, B. Moldobekov and S. Parolai (2013). Improving the spatial resolution of ground motion variability using earthquake and seismic noise data: the example of Bishkek (Kyrgyzstan), Bull. Earthq. Eng., 11, 385-399.

Ullah, S., D. Bindi, M. Pilz and S. Parolai (2015). Probabilistic seismic hazard assessment of Bishkek, Kyrgyzstan, considering empirically estimated site effects, Annals of Geophysics, 58 (1), S0105; doi:10.4401/ag6682.

Ulomov, V.I., and B.Z. Mavashev (1971). The Tashkent earthquake of 26 April 1966, Akad. Nank. Uzbek. SSR FAN, 188, Tashkent, Uzbek SSR.

Woolery, E.W., and R. Street (2002). 3D near-surface soil response from $\mathrm{H} / \mathrm{V}$ ambient noise ratios, Soil Dyn. Earthq. Eng., 22, 865-876.

Zodotarow, G.S., W.S. Fachorenko, W.I. Lipmija, D. Hergow, N.A. Rohdijow and P. Jaodokowa (undated). Polygon based engineering and geological map of the Dushanbe region, Soviet Academy of Science, Moscow, USSR (in Russian).

\footnotetext{
${ }^{\star}$ Corresponding author: Marco Pilz, Helmholtz Center Potsdam - German Research Center for Geosciences, Potsdam, Germany; email: pilz@gfz-potsdam.de.

(C) 2015 by the Istituto Nazionale di Geofisica e Vulcanologia. All rights reserved.
} 